\title{
Novel conductive polypyrrole/zinc oxide/chitosan bionanocomposite: synthesis, characterization, antioxidant, and antibacterial activities
}

This article was published in the following Dove Press journal:

International Journal of Nanomedicine

30 December 2014

Number of times this article has been viewed

\author{
Saeideh Ebrahimias| ${ }^{1,2}$ \\ Azmi Zakaria ${ }^{3}$ \\ Anuar Kassim ${ }^{4}$ \\ Sri Norleha Basri ${ }^{4}$ \\ 'Department of Nanotechnology, \\ Institute of Advanced Technology, \\ Universiti Putra Malaysia, Serdang, \\ Malaysia; ${ }^{2}$ Department of Chemistry, \\ Ahar Branch, Islamic Azad University, \\ Ahar, Iran; ${ }^{3}$ Department of Physics, \\ Universiti Putra Malaysia, Serdang, \\ Malaysia; ${ }^{4}$ Department of Chemistry, \\ Universiti Putra Malaysia, Serdang, \\ Malaysia
}

\begin{abstract}
An antibacterial and conductive bionanocomposite (BNC) film consisting of polypyrrole (Ppy), zinc oxide (ZnO) nanoparticles (NPs), and chitosan (CS) was electrochemically synthesized on indium tin oxide (ITO) glass substrate by electrooxidation of $0.1 \mathrm{M}$ pyrrole in aqueous solution containing appropriate amounts of ZnO NPs uniformly dispersed in CS. This method enables the room temperature electrosynthesis of BNC film consisting of ZnO NPs incorporated within the growing Ppy/CS composite. The morphology of Ppy/ZnO/CS BNC was characterized by scanning electron microscopy. ITO-Ppy/CS and ITO-Ppy/ZnO/CS bioelectrodes were characterized using the Fourier transform infrared technique, X-ray diffraction, and thermogravimetric analysis. The electrical conductivity of nanocomposites was investigated by a four-probe method. The prepared nanocomposites were analyzed for antioxidant activity using the 2,2-diphenyl-1-picrylhydrazyl assay. The results demonstrated that the antioxidant activity of nanocomposites increased remarkably by addition of ZnO NPs. The electrical conductivity of films showed a sudden decrease for lower weight ratios of $\mathrm{ZnO}$ NPs (5 wt\%), while it was increased gradually for higher ratios $(10,15$, and $20 \mathrm{wt} \%)$. The nanocomposites were analyzed for antibacterial activity against Gram-positive and Gram-negative bacteria. The results indicated that the synthesized BNC is effective against all of the studied bacteria, and its effectiveness is higher for Pseudomonas aeruginosa. The thermal stability and physical properties of BNC films were increased by an increase in the weight ratio of ZnO NPs, promising novel applications for the electrically conductive polysaccharide-based nanocomposites, particularly those that may exploit the antimicrobial nature of Ppy/ZnO/CS BNCs.
\end{abstract}

Keywords: bionanocomposite, electrodeposition, conductive, antibacterial, antioxidant

\section{Introduction}

Nowadays, a great deal of attention is received for the use of conductive polymers such as polyaniline, polythiophene, and polypyrrole (Ppy) because of their unique physical and electroconductive properties. ${ }^{1-4}$ Among them, Ppy is an ideal electroactive polymer for drug-delivery applications because of its favorable biocompatibility and antioxidant activity. The fact that Ppy can be made in degradable forms enhances its value for biomedical application. ${ }^{5-10}$ However, it is chemically sensitive and has poor mechanical properties and thus poses a processability problem. ${ }^{11,12}$ To improve the structural and physical properties of Ppy, much research have been done to form a composite of Ppy with conventional polymers. ${ }^{13-16}$ Therefore, a new generation of the conductive composites of Ppy/cellulose with high galvanostatic cycling stability (for use in flexible energy devices), high thermal stability (for use in nanofibrous membrane), high sensitivity (for use in gas sensors and biosensors), high-capacity electrochemical control solid state material (for the release of deoxyribonucleic acid
Correspondence: Saeideh Ebrahimiasl Department of Nanotechnology, Institute of Advanced Technology, Universiti Putra Malaysia, 43400 Serdang, Malaysia

Tel +60 I 73136059

Fax +60389466808

Email ebrahimiasl.saeideh@yahoo.com 
oligomers), and enhanced ion absorption capacity has been developed. ${ }^{17-26}$ Recently, electroactive Ppy/chitosan (CS) composite nanospheres and highly conductive Ppy/cellulose nanocomposite films with enhanced mechanical properties were introduced. ${ }^{27,28}$

CS as a biodegradable, biocompatible, nontoxic, and lowcost biopolymer was used to prepare Ppy/CS composite films with the aim of increasing the mechanical, ${ }^{29}$ antibacterial, ${ }^{30}$ electrochemical, ${ }^{31}$ and biocompatible properties of the resulting products. ${ }^{32}$ Also, its unique properties allow rapid blood clotting or transdermal drug delivery. ${ }^{33}$ Furthermore, its solubility in aqueous medium expands its application for food packaging films, bone substitutes, and artificial skin. ${ }^{34}$

On the other hand, organic-inorganic nanocomposite materials attracted substantial attention because of the possibility of combining the properties of organic and inorganic components. ${ }^{35-38}$ Conductive polymers and oxide nanocomposites have brought out more fields of application, such as biosensors, gas sensors, conductive paints, drug delivery, and rechargeable batteries. ${ }^{39-42}$ Among the metal oxide nanoparticles (NPs), zinc oxide ( $\mathrm{ZnO}$ ) NPs have been exploited as a potential material for biosensing and gas sensing because of their unusual properties, including high surface area, high catalytic efficiency, nontoxicity, chemical stability, and strong adsorption ability (high isoelectric point 9.5). ${ }^{43-46}$ Thus, bionanocomposites (BNCs) formed by combining conducting polymers, $\mathrm{CS}$, and $\mathrm{ZnO}$ NPs possess all of the good properties of all constituents.

Among the different preparation methods, significant interest has been generated in the application of electrodeposition for the fabrication of nanocomposite films containing metal oxide NPs in a polymer matrix. Compared with other methods such as layer-by-layer self-assembly, electrodeposition offers the advantages of higher deposition rate, shorter processing time, and the possibility of the deposition of thick films at room temperature. Moreover, uniform films of controlled composition with complex shapes can be obtained on the selected areas of the substrates. The fabrication of composite films can be achieved by electrochemical codeposition of organic and inorganic components. $^{47,48}$

\section{Experiment}

\section{Materials and methods}

The pyrrole monomer (Fluka St Gallen, Switzerland) was distilled prior to use and stored at $4^{\circ} \mathrm{C}$. $\mathrm{ZnO}$ nanopowder and acetic acid were supplied by Sigma-Aldrich Co. (St Louis, MO, USA). The sodium salt of p-toluene sulfonic acid (p-TS)
(Sigma-Aldrich) was used as dopant. CS (molecular weight 600,000-800,000) (98.0\%) was supplied by Acros Organics (Thermo Fisher Scientific, Fair Lawn, NJ, USA). In the first step, CS powder was dissolved (in grams) in $1 \%$ acetic acid solution. The mixture was left at the laboratory for 5 hours and then stirred continuously with a magnetic stirrer for several minutes at room temperature until the CS powder was completely dissolved in the solution.

The ZnO NPs with different weight ratios (5-20 wt\%) were dispersed in distilled water and sonicated for 4 hours to obtain a well-dispersed suspension and enhance the disaggregation of NPs. Then it was added to the CS solution under vigorous stirring. Electrochemical deposition of Ppy/ZnO/CS BNC film was performed using a potentiostat (Elchema, Potsdam, New York, NY, USA, Model: PS 605) on the indium tin oxide (ITO) glass (Sigma-Aldrich) surface. The film was prepared in a solution with the concentrations of $0.3 \mathrm{M}$ Ppy, 0.1 M p-TS, and $0.7 \%(w / v) ~ C S$. The deposition was performed at a constant voltage of 1.2 volts (vs standard calomel electrode [SCE]) for 1 hour and 30 minutes. The film was rinsed thoroughly with distilled water, peeled off from the electrode, and dried in an oven at $45^{\circ} \mathrm{C}$ for 4 hours. Figure 1 shows a schematic view of the growing polymer's chains on the surface of ITO glass in the presence of $\mathrm{ZnO}$ NPs and in CS-free solution.

\section{Apparatus}

All electroplating experiments were performed using a potentiostat (Model: PS 605). The electrochemical cell consisted of a three-electrode arrangement with a carbon rod counter electrode (Metrohm, Switzerland) and a saturated calomel reference electrode (Metrohm) with an ITO glass working electrode.

Molecular analysis of the samples was performed by Fourier transform infrared (FTIR) spectroscopy (PerkinElmer, Santa Clara, CA, USA), recorded over the range of 200-4,000 $\mathrm{cm}^{-1}$. X-ray diffraction (XRD) experiments were carried out on an XRD-6000 instrument (Shimadzu, Osaka, Japan), and the patterns were recorded at a scan speed of $4^{\circ}$ per minute with $\mathrm{Cu} \mathrm{K} \alpha 1$ radiation $(\lambda=1.54060 \AA)$ operating at $40 \mathrm{kV}$ and $40 \mathrm{~mA}$.

A standard four-point probe technique (Jandel Resistivity Test Unit, Kings Langley, UK) was used to measure the electrical direct current conductivity of the $\mathrm{Ppy} / \mathrm{ZnO} / \mathrm{CS}$ conducting composite films. The thermostability property of the prepared composite was analyzed using the Mettler Toledo TGA/SDTA 851 thermogravimetric analyzer. For the analysis, $20-25 \mathrm{mg}$ of the sample was heated from $-50^{\circ} \mathrm{C}$ to $500^{\circ} \mathrm{C}$ at the rate 


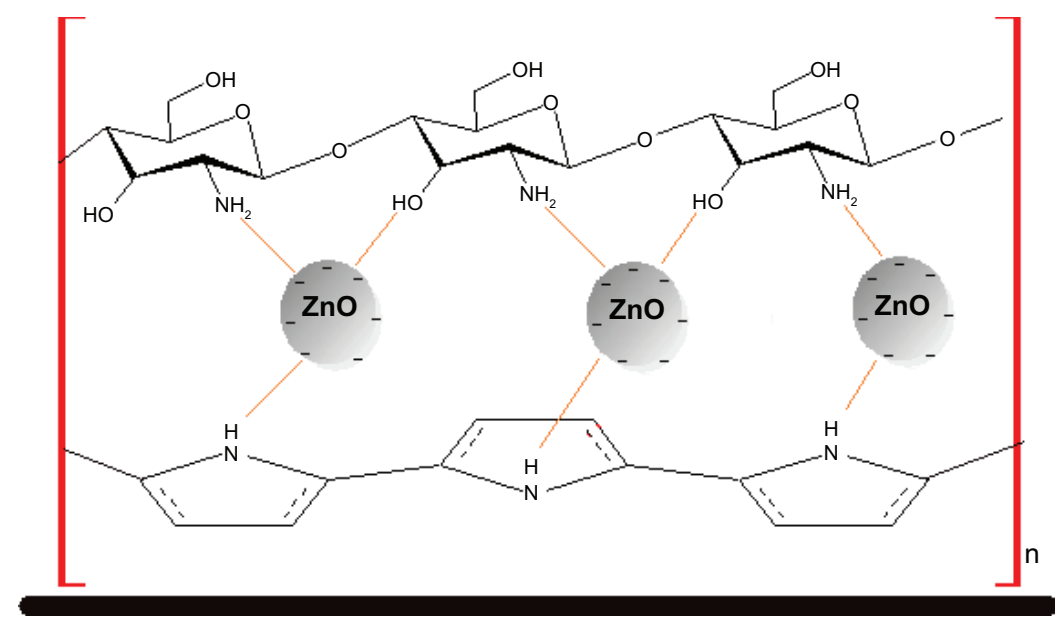

Figure I Schematic illustration of the synthesized polypyrrole/zinc oxide ( $\mathrm{ZnO}) /$ chitosan bionanocomposite film at the surface of the electrode.

of $5^{\circ} \mathrm{C} / \mathrm{min}$, with a nitrogen gas flow rate of $50 \mathrm{~mL} / \mathrm{min}$. The weight and percentage of the residue were recorded to determine the weight loss of the sample after heating.

Electron microscopy investigations of the films were performed using an LEO 1455 (JEOL, Eching, München, Germany) scanning electron microscope (SEM).

The dynamic mechanical analysis (DMA) was done using a PerkinElmer (Pyris Diamond, Germany) analyzer working in tensional mode. DMA analysis was done in the temperature range of $25^{\circ} \mathrm{C}-250^{\circ} \mathrm{C}$ with a heating rate of $2^{\circ} \mathrm{C}$ per minute at a frequency of $1 \mathrm{~Hz}$ under nitrogen atmosphere. Sample dimensions were typically kept quite constant to ensure reproducibility $(40 \mathrm{~mm} \times 60 \mathrm{~mm})$.

\section{Evaluation of antibacterial activity}

The in vitro antibacterial activity of the samples was evaluated by the well diffusion method using Mueller-Hinton agar through determining the diameter of the inhibition zone formed around the well, which was confirmed to be at the recommended standards of the National Committee for Clinical Laboratory Standards (NCCLS, 2000). Petri plates containing $20 \mathrm{~mL}$ Mueller-Hinton medium were seeded with 24-hour culture of bacterial strains. The wells were cut and $20 \mu \mathrm{L}$ of the BNC solution was added. The plates were then incubated at $37^{\circ} \mathrm{C}$ for 24 hours. Streptomycin antibiotic was used as a positive control, and dimethyl sulfoxide was used as a negative control.

\section{Evaluation of antioxidant activity}

The antioxidant activity of BNCs was evaluated by the scavenging activity of 2,2-diphenyl-1-picrylhydrazyl (DPPH) as a stable free radical. Maximum absorption of the DPPH free radicals with an odd electron at $517 \mathrm{~nm}$ decreased due to reaction with BNC. The free radicals of DPPH become paired off in the presence of a hydrogen donor and reduced to DPPHH or converted into DPPH anion through electron transfer reaction. ${ }^{49}$

For antioxidant activity measurement, $25 \mathrm{mg}$ of DPPH was dissolved in $100 \mathrm{~mL}$ of ethanol, and then $1 \mathrm{~mL}$ of this solution was mixed with $1,2,3,4$, and $5 \mathrm{mg}$ of BNCs with different contents of $\mathrm{ZnO}$ NPs. The reaction mixture was shaken for 30 seconds and incubated in dark conditions at $25^{\circ} \mathrm{C}$ for 15 minutes, after which the wavelength scanning was performed using an ultraviolet-visible spectrophotometer. The absorbance was measured at $517 \mathrm{~nm}$ at different time intervals and room temperatures. A decrease in the absorbance of the DPPH solution indicates an increase in the antioxidant activity. The DPPH inhibition was calculated as follows:

$$
\% \text { of DPPH inhibition }=\frac{A_{b}-A_{S}}{A_{b}} \times 100
$$

where $A_{b}$ is the absorption of the blank and $A_{s}$ is the absorption of the sample.

\section{Results and discussion}

The results of FTIR studies are shown in Figure 2. The FTIR spectrum of commercial $\mathrm{ZnO}$ powder showed a band below $500 \mathrm{~cm}^{-1}$ related to the characteristic adsorptions of $\mathrm{ZnO} .{ }^{50-52}$ The broad peak at $\sim 3,120 \mathrm{~cm}^{-1}$ can be attributed to the vibration of $\mathrm{OH}$ groups of the adsorbed water molecules, and other small peaks $1,233,1,348$, and $1,750 \mathrm{~cm}^{-1}$ are related to the adsorbed carbonate moieties. ${ }^{51,53}$ 


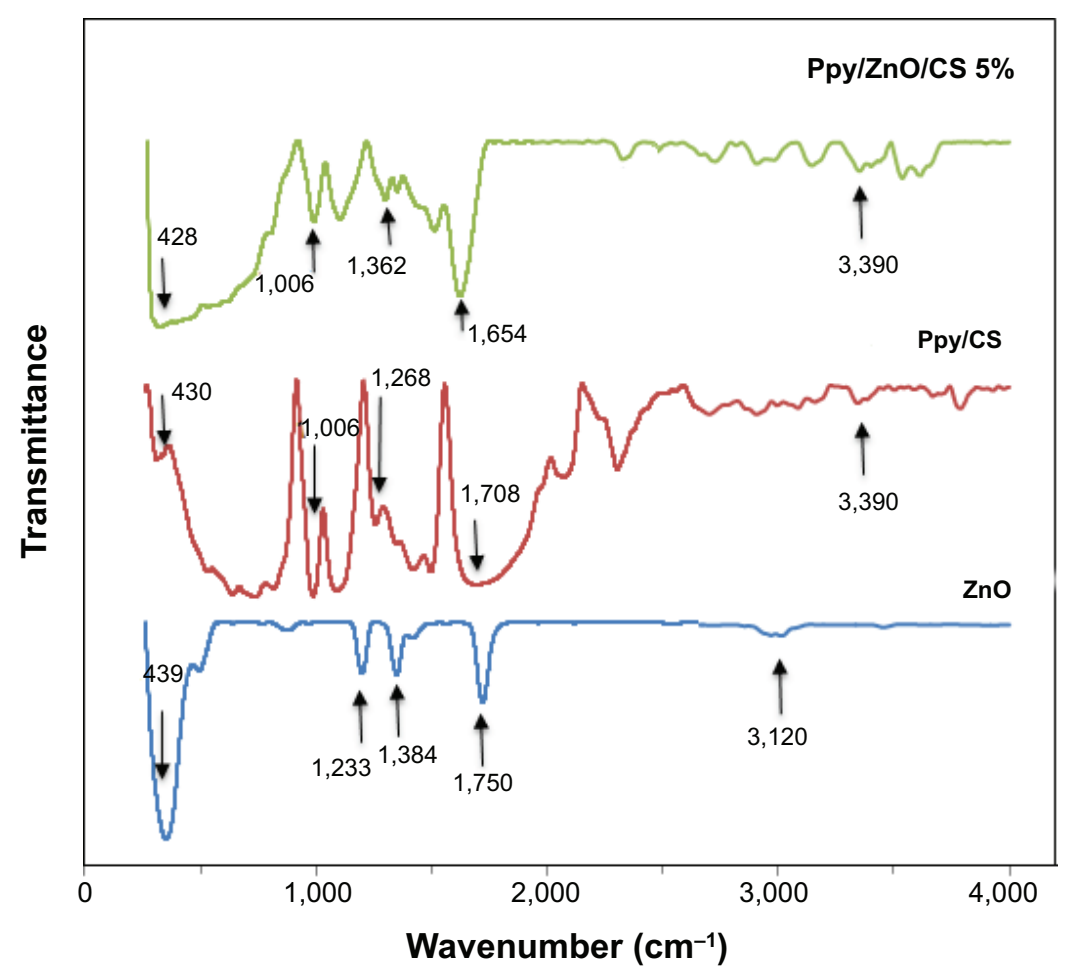

Figure 2 Fourier transform infrared spectra for zinc oxide nanopowder, deposited film of Ppy/CS composite, and Ppy/ZnO/CS composite film. Note: Arrows show the position of characteristic peaks.

Abbreviations: Ppy, polypyrrole; CS, chitosan; $\mathrm{ZnO}$, zinc oxide.

The FTIR spectrum of Ppy/CS composite film (Figure 2) showed a peak around 3,390 $\mathrm{cm}^{-1}$ related to the $\mathrm{N}-\mathrm{H}$ stretching of pyrrole and the $\mathrm{O}-\mathrm{H}$ stretching of $\mathrm{CS}$. A peak at $1,708 \mathrm{~cm}^{-1}$ is attributed to $\mathrm{C}=\mathrm{O}$ (acetylated amino) stretching mode, and is evidence toward the formation of Ppy/CS composite. ${ }^{29}$ The peak at $1,320 \mathrm{~cm}^{-1}$, which is assigned to the $-\mathrm{C}-\mathrm{O}$ stretching mode of $-\mathrm{CH}_{2}-\mathrm{OH}$ groups in $\mathrm{CS}$, has shifted to lower wave numbers in Ppy/CS composite film. A peak around $1,006 \mathrm{~cm}^{-1}$ is related to the $\mathrm{C}-\mathrm{O}$ stretching of CS, which has overlapped with Ppy. ${ }^{29,54,55}$

The FTIR spectrum of Ppy/ZnO/CS film showed that the peaks observed in the spectrum of Ppy/CS composite (at 1,708 and 1,320 $\mathrm{cm}^{-1}$ ) have shifted to 1,654 and $1,362 \mathrm{~cm}^{-1}$, respectively. A similar shift was reported in the literature and was attributed to the formation of $\mathrm{Ppy} / \mathrm{ZnO} /$ CS complexes. ${ }^{29,56,57}$

Figure 3 shows the XRD patterns of $\mathrm{Ppy} / \mathrm{ZnO} / \mathrm{CS}$ composite and pure Ppy/CS and $\mathrm{ZnO}$ nanopowder. The XRD pattern of Ppy/CS composite showed a broad scattering peak, which indicates a highly amorphous structure for Ppy/ CS arising from the Ppy chains close to the interplanar van der Waals distance for aromatic groups. ${ }^{58,59}$ The diffraction patterns for Ppy/ZnO/CS composite showed the peaks of $\mathrm{ZnO}$ phase (JCPDS file 075-1533) corresponding to (101) and (100) reflections. The intensity of the peaks in the XRD patterns increases with the increase in the content of $\mathrm{ZnO}$ NPs up to $10 \%$, where peaks become sharper.

The direct current conductivity of the $\mathrm{Ppy} / \mathrm{ZnO} / \mathrm{CS}$ BNCs was studied by increasing the percentage of $\mathrm{ZnO}$ NPs from $5 \%$ to $20 \%$. The composite was prepared with a fixed concentration of pyrrole $(0.3 \mathrm{M}), \mathrm{CS}(0.7 \% \mathrm{w} / \mathrm{v})$, and p-TS $(0.1 \mathrm{M})$. Table 1 shows that the conductivity of the

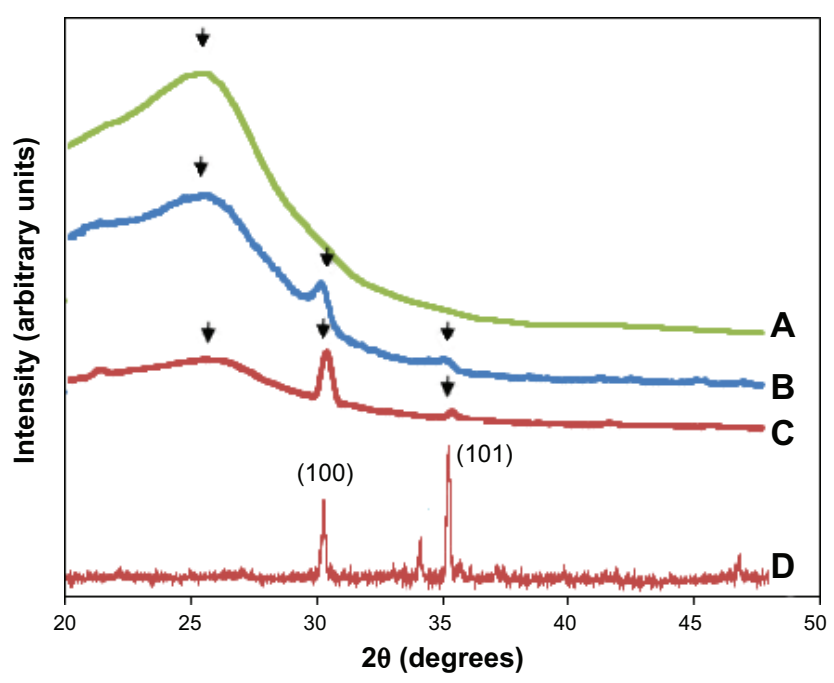

Figure 3 X-ray diffraction patterns of (A) pure Ppy/CS, (B) Ppy/ZnO/CS 5\%, (C) Ppy/ZnO/CS I0\% composite films, and (D) ZnO nanopowder.

Abbreviations: Ppy, polypyrrole; CS, chitosan; $\mathrm{ZnO}$, zinc oxide. 
Table I Characteristics of the investigated $\mathrm{Ppy} / \mathrm{ZnO} / \mathrm{CS}$ bionanocomposites

\begin{tabular}{llll}
\hline Sample & $\begin{array}{l}\text { ZnO nanoparticles } \\
\text { content }(\mathbf{w t} \%)\end{array}$ & $\begin{array}{l}\text { Conductivity } \\
\left(\mathbf{S} \cdot \mathbf{c m}^{-1}\right)\end{array}$ & $\begin{array}{l}\text { Thickness } \\
(\mathbf{m m})\end{array}$ \\
\hline Ppy/CS & 0.0 & 62.36 & 0.10 \\
Ppy/ZnO/CS & 5.0 & 33.55 & 0.98 \\
Ppy/ZnO/CS & 10 & 54.64 & 0.10 \\
Ppy/ZnO/CS & 15 & 56.95 & 0.10 \\
Ppy/ZnO/CS & 20 & 61.15 & 0.99 \\
\hline
\end{tabular}

Abbreviations: Ppy, polypyrrole; CS, chitosan; $\mathrm{ZnO}$, zinc oxide; wt, weight.

$\mathrm{Ppy} / \mathrm{ZnO} / \mathrm{CS} \mathrm{BNCs}$ is decreased from $62.36 \mathrm{~S} \cdot \mathrm{cm}^{-1}$ to $33.55 \mathrm{~S} \cdot \mathrm{cm}^{-1}$ with the addition of ZnO NPs to the Ppy/CS matrix. In Ppy/CS composite the presence of CS can be linked to the pyrrole to increase the conjugation length of the polymer and electrical conductivity. ${ }^{60}$ The addition of $\mathrm{ZnO}$ NPs interrupts the conjugation between the layers of Ppy and CS and, as a result, the conductivity is decreased. With a gradual increase in $\mathrm{ZnO} \mathrm{NP}$ ratio up to $20 \mathrm{wt} \%$, an intermediate layer of $\mathrm{ZnO}$ NPs is formed between CS and Ppy layers, in which the charge transfer takes place by the weak partial charges on the surface of $\mathrm{ZnO}$ NPs. So the conductivity increases to $61.15 \mathrm{~S} \cdot \mathrm{cm}^{-1}$.

The results of thermogravimetric analysis (TGA) are shown in Figure 4. The first weight loss for Ppy/CS composite occurred at the temperatures between $35^{\circ} \mathrm{C}$ and $151^{\circ} \mathrm{C}$ and showed $4.3 \%$ mass loss. Since Ppy is hygroscopic, during the heating up to $150^{\circ} \mathrm{C}$, the polymer loses the residual water. ${ }^{59}$ The rapid loss, corresponding to polymer degradation, occurred in the temperature range $165^{\circ} \mathrm{C}-630^{\circ} \mathrm{C}$. Ppy showed a residue of $63 \%$ weight retention at $708^{\circ} \mathrm{C}$.

The comparison of TG curve of Ppy/CS with $\mathrm{Ppy} / \mathrm{ZnO} /$ CS is also shown in Figure 4. The evaluated mass loss of

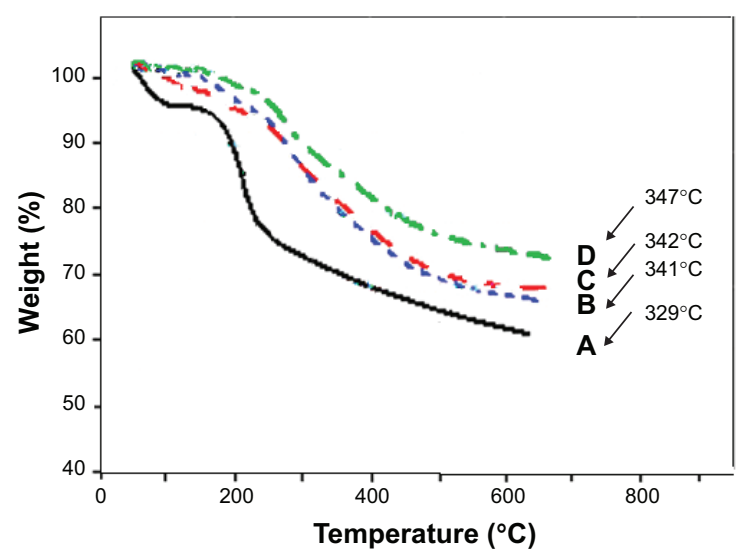

Figure 4 Thermogravimetric curves of (A) Ppy/CS composite, (B) Ppy/CS composite with 10\%, (C) 15\%, and (D) 20\% ZnO nanoparticles. Abbreviations: Ppy, polypyrrole; CS, chitosan; $\mathrm{ZnO}$, zinc oxide.
$\mathrm{Ppy} / \mathrm{ZnO} / \mathrm{CS} \mathrm{BNC}$ during the heating up to $150^{\circ} \mathrm{C}$ showed a decrease with the increase in $\mathrm{ZnO}$ NP content, indicating that the affinity of composite toward humidity decreases while $\mathrm{ZnO}$ NP content is increased. The second mass loss for the composite film prepared from $5.0 \mathrm{wt} \%$ of $\mathrm{ZnO}$ NPs started at $175^{\circ} \mathrm{C}$, and the residual sample mass was increased with increase of $\mathrm{ZnO} N \mathrm{NP}$ content to $20 \mathrm{wt} \%$. This suggests that $\mathrm{ZnO}$ NPs can improve the thermal stability of Ppy/ZnO/CS BNC.

A summary of the mechanical parameters of the Ppy/ $\mathrm{ZnO} / \mathrm{CS}$ BNC films calculated from the stress-strain curves in different temperatures is shown in Figure 5. All films exhibited a near linear elastic behavior until the film scaffolds broke. The tensile strength of the scaffolds increased with increasing of the $\mathrm{ZnO} \mathrm{NP}$ content. As shown in Figure 5A, the incorporation of $\mathrm{ZnO}$ NPs caused the storage modulus of the scaffolds to increase from $42 \pm 5.0 \mathrm{MPa}$ for pure Ppy/ CS films to $79 \pm 3.3,84 \pm 1.0$, and $92 \pm 3.6 \mathrm{MPa}$ for the Ppy/ CS films prepared with $0.0 \%, 5.0 \%, 10 \%$, and $15 \%$ of $\mathrm{ZnO}$ NPs. These results indicated that increasing the content of $\mathrm{ZnO}$ NPs in the blended solutions reduced the strength of the resultant nanocomposite and increased the elasticity of the nanofilms scaffolds. Figure $5 \mathrm{~B}$ shows the temperature dependence of the storage modulus of Ppy film, Ppy/CS composite film, and Ppy/CS composite film with different contents of ZnO NPs. It can be seen that the Ppy film has a very low storage modulus value in the measured temperature range; however, when CS is combined with Ppy, the storage modulus (E') is increased. Likewise, ZnO NPs increase the mechanical properties of Ppy/CS composite. It is obvious that the storage modulus of prepared Ppy/ZnO/CS BNCs increases by increasing the ratio of $\mathrm{ZnO}$ NPs from $5 \mathrm{wt} \%$ to $15 \mathrm{wt} \%$. This is also evidence of the incorporation of $\mathrm{ZnO}$ NPs into the composite structure.

The SEM images of Ppy, Ppy/CS, and Ppy/ZnO/CS $(20 \%)$ BNCs films are shown in Figure 6. Figure 6A shows the surface morphology of the Ppy film. The microstructure of a Ppy thin film has a uniform granular morphology and its average grain size is $\sim 200-400 \mathrm{~nm}$. Figure $6 \mathrm{~B}$ shows the surface morphology of the Ppy/CS film. The image shows that the Ppy/CS film has small globular morphology with spherical ball shapes with an average grain size of about 100-1,000 nm. The SEM image of the Ppy/ZnO/CS (20\%) $\mathrm{BNC}$ is shown in Figure 6C. It clearly shows the uniform distribution of ZnO NPs into the Ppy/CS matrix, which indicates that $\mathrm{ZnO}$ NPs had interaction with the Ppy/CS composite. The increase in conjugation length in Ppy/CS composite is the reason for an increase in particle size of deposited film. 
A
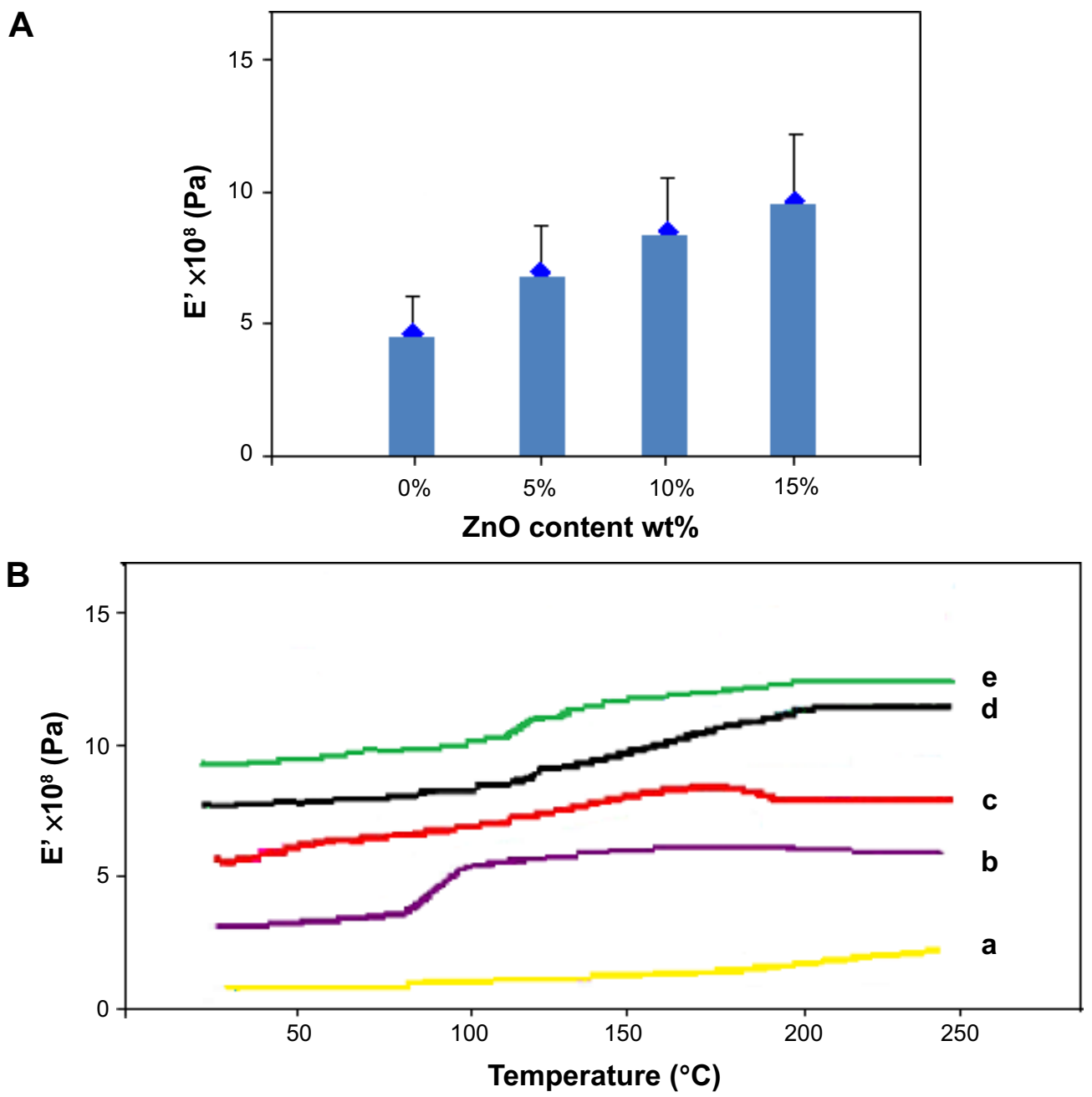

Figure 5 Mechanical properties of the Ppy/CS nanocomposite.

Notes: (A) Storage modulus (E') versus ZnO NP content and (B) storage modulus (E') versus temperature for (a) Ppy and Ppy/CS films prepared with (b) $0.0 \%$, (c) 5.0\%, (d) $10 \%$, and (e) $15 \%$ of $\mathrm{ZnO}$ NPs.

Abbreviations: Ppy, polypyrrole; CS, chitosan; $\mathrm{ZnO}$, zinc oxide; NP, nanoparticle; wt, weight.

Meanwhile, a disturbance in cross-linking of the Ppy and CS layers due to the presence of $\mathrm{ZnO}$ NPs decreased the particle size of the $\mathrm{Ppy} / \mathrm{ZnO} / \mathrm{CS}$ composite.

Such morphology is preferred for gas sensing and catalytic application, as it promotes adsorption of different biological and gas molecules through the film surface, so excellent sensitivity can be expected. ${ }^{61,62}$ All of these micrographs confirm the lack of phase separation of the films, supporting the homogeneous film formation of Ppy with $\mathrm{CS}$ and $\mathrm{ZnO}$ NPs. Figure 6D, E, and F shows the energy-dispersive X-ray fluorescence (EDXRF) spectra for the Ppy, Ppy/CS, and Ppy/ $\mathrm{ZnO} / \mathrm{CS}$ BNCs. The peaks at around 0.3 and $0.4 \mathrm{keV}$ are related to the binding energies of carbon and nitrogen in the Ppy structure. The binding energy of oxygen was observed around $0.5 \mathrm{keV}$, which can be related to the oxidation form of pyrrole. The intensity of these peaks was increased by the presence of CS in Figure 6E. In Figure 6F, the peaks around
$0.9,7.8,8.3$, and $8.8 \mathrm{keV}$ are related to $\mathrm{Zn}^{2+}$ elements. Therefore, the EDXRF spectra for the Ppy, Ppy/CS, and Ppy/ZnO/ CS BNCs confirmed the presence of elemental compounds in the Ppy, CS, and ZnO NPs without any impurity peaks. The intensity of the peaks is in agreement with elemental composition of synthesized BNC.

Numerous studies have been constructed for CS bacteriostatic/bactericidal activity to control the growth of algae and to inhibit viral multiplication. ${ }^{63-66} \mathrm{CS}$ has several advantages over other types of disinfectants because of higher antibacterial activity, a broader spectrum of bactericidal activity, a higher killing rate, and a lower toxicity toward mammalian cells. ${ }^{67,68}$ The investigation of the antibacterial properties of nano- $\mathrm{ZnO}$ has shown that the $\mathrm{ZnO}$-assembled cotton fibers have antibacterial circle width of about $1.5-2.3 \mathrm{~mm}$ and 2.3-3.4 mm against Escherichia coli and Staphylococcus aureus, respectively. It has also been indicated that the 

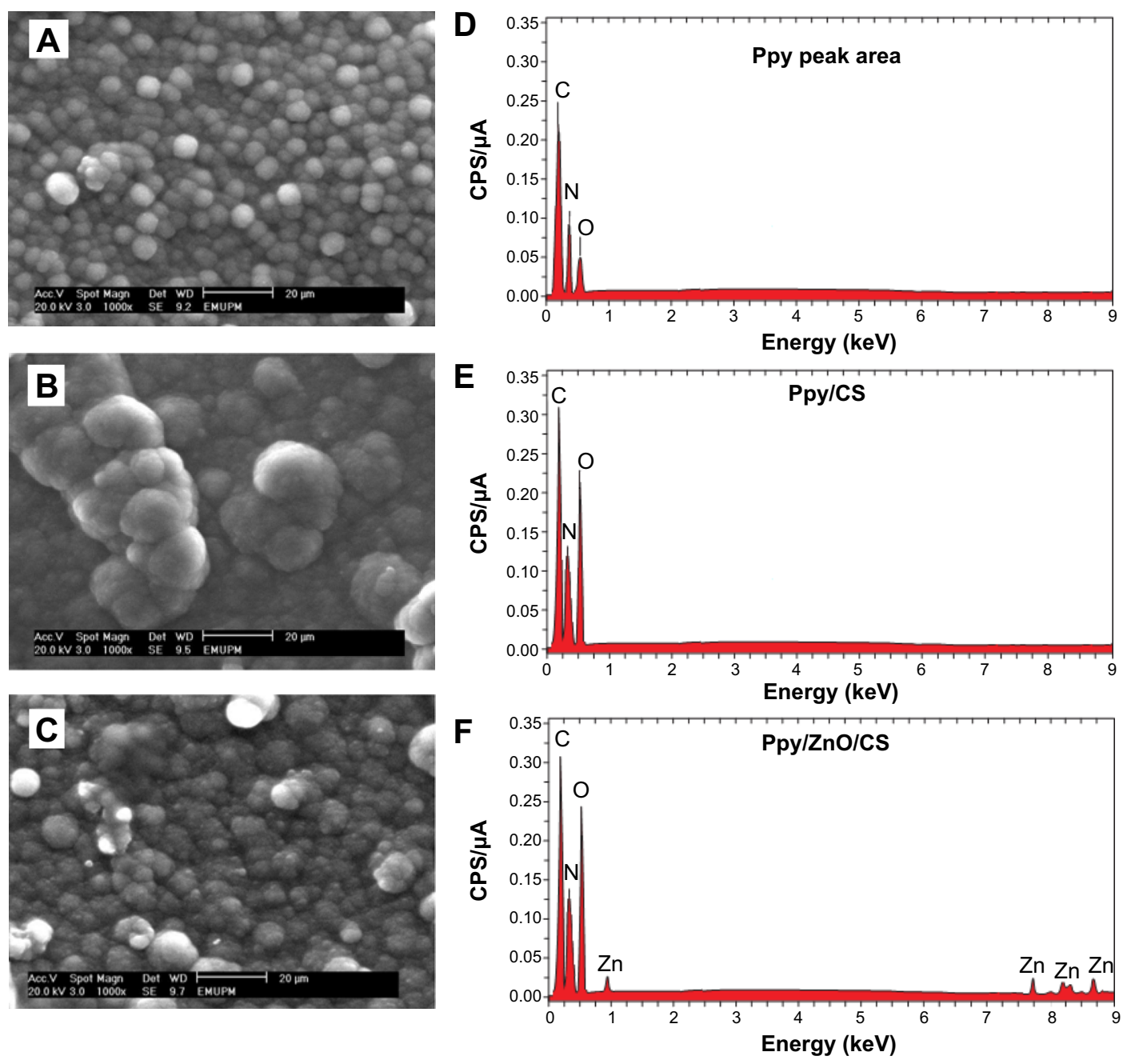

Figure 6 Scanning electron microscopy images and energy-dispersive X-ray fluorescence spectra of (A, D) Ppy, (B, E) Ppy/CS, and (C, F) Ppy/ZnO/CS (20 wt\%). Abbreviations: Ppy, polypyrrole; CPS, counts per second; CS, chitosan; wt, weight; $\mathrm{ZnO}$, zinc oxide.

antibacterial activity of fibers increases with decreasing $\mathrm{ZnO}$ size and increasing $\mathrm{ZnO}$ content. ${ }^{69}$ Several mechanisms have been argued for the antibacterial activity of NPs, including generation of oxygen species to degradation of cell structure or release of ions from the surface of NPs to binding the cell membrane. ${ }^{70-73}$ This result reinforces the idea that the lipopolysaccharide proteins in the cell wall structures of
Gram-negative bacteria protect them against NP attacks. ${ }^{74}$ Also, well inclination of NPs to amino and carboxyl groups on the cell walls of Gram-positive bacteria is the reason for the inhibitory effect of NPs against these bacteria. ${ }^{75}$

The evaluation of antibacterial activity of the synthesized Ppy/ZnO/CS BNCs was tested against Gram-positive and Gram-negative bacteria (Table 2 and Figure 7) and was

Table 2 Average inhibition zone for Ppy/ZnO/CS bionanocomposites with different content of $\mathrm{ZnO}$ nanoparticles

\begin{tabular}{|c|c|c|c|c|c|c|}
\hline \multirow[t]{2}{*}{ Bacteria } & & \multicolumn{4}{|c|}{ Inhibition zone (mm) } & \multirow{2}{*}{$\begin{array}{l}\text { Control } \\
\text { positive }(\mathrm{mm}) \\
\mathrm{SM}\end{array}$} \\
\hline & & $\begin{array}{l}\text { Ppy/ZnO/CS } \\
(5 \%)\end{array}$ & $\begin{array}{l}\text { Ppy/ZnO/CS } \\
(10 \%)\end{array}$ & $\begin{array}{l}\text { Ppy/ZnO/CS } \\
\text { (I5\%) }\end{array}$ & $\begin{array}{l}\text { Ppy/ZnO/CS } \\
(20 \%)\end{array}$ & \\
\hline \multirow[t]{2}{*}{ Gram-positive } & Staphylococcus aureus & $9.02 \pm 0.061$ & $14.53 \pm 0.030$ & $18.36 \pm 0.010$ & $28.63 \pm 0.010$ & $21.2 \pm 0.020$ \\
\hline & Bacillus cereus & $15.62 \pm 0.078$ & $|8.26 \pm 0.06|$ & $19.18 \pm 0.030$ & $20.83 \pm 0.017$ & $21.2 \pm 0.058$ \\
\hline \multirow[t]{2}{*}{ Gram-negative } & Pseudomonas aeruginosa & $20.54 \pm 0.14 \mid$ & $23.85 \pm 0.034$ & $25.42 \pm 0.046$ & $29.60 \pm 0.010$ & $29.1 \pm 0.045$ \\
\hline & Escherichia coli & $9.00 \pm 0.043$ & $11.89 \pm 1.076$ & $15.30 \pm 0.0173$ & $17.70 \pm 0.026$ & $21.2 \pm 0.028$ \\
\hline
\end{tabular}

Note: Data shown are mean \pm standard deviation.

Abbreviations: Ppy, polypyrrole; CS, chitosan; ZnO, zinc oxide; SM, streptomycin. 


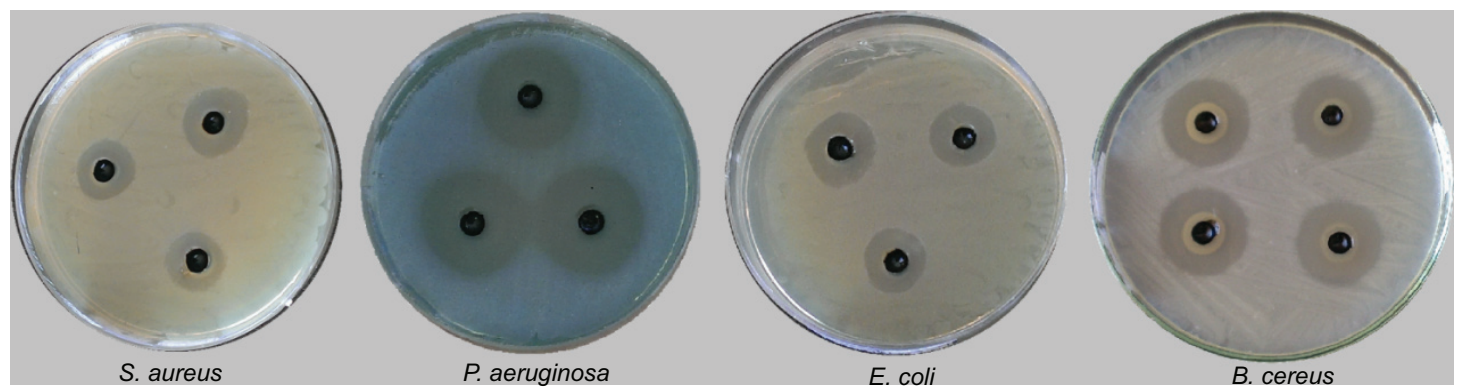

Figure 7 The antibacterial activity of Ppy/ZnO/CS bionanocomposite with 5\% ZnO nanoparticle content evaluated by well diffusion method against Staphylococcus aureus, Pseudomonas aeruginosa, Escherichia coli, and Bacillus cereus bacteria (the test repeated three times for each sample).

Abbreviations: Ppy, polypyrrole; $\mathrm{CS}$, chitosan; $\mathrm{ZnO}$, zinc oxide.

conducted with the fixed concentration of Ppy $(0.3 \mathrm{M})$ and CS $(0.7 \% \mathrm{w} / \mathrm{v})$. The test was repeated three times for each treated sample, and the inhibition zone values are presented as average values in Table 2. The results showed that Ppy/ $\mathrm{ZnO} / \mathrm{CS}$ BNCs have high antibacterial activity against Grampositive and Gram-negative bacteria. The inhibitory effect of BNCs was increased with the increase in the content of $\mathrm{ZnO}$ NPs. This indicates that ZnO NPs are the effective portion of BNC that causes its antibacterial activity. Maximum inhibition was observed for the Ppy/ZnO/CS composite with $20 \mathrm{wt} \% \mathrm{ZnO} \mathrm{NP}$ and against Pseudomonas aeruginosa bacteria about $29.60 \mathrm{~mm}$, which is comparable with the streptomycin inhibition values.

The results of the free radical scavenging capability of the $\mathrm{BNC}$ were detected in reaction with DPPH free radicals. It was revealed that there was a progressive decrease in the absorption band of DPPH at $517 \mathrm{~nm}$ with increase in the weight ratio of nanomaterial. The chemical structure of the materials is critical for their capability to donate active hydrogen atom or transfer electron to reduce DPPH. Different studies have been conducted on the antioxidant activity of Ppy and
Ppy/CS composite. Hsu et $\mathrm{al}^{76}$ optimized the ratio of APS/ pyrrole for the synthesis of Ppy with a better DPPH free radical scavenging. Lee et $\mathrm{al}^{17}$ showed that the antioxidant activity of Ppy/CS composite was affected by the partial overoxidization of Ppy at higher APS concentrations. Hsu et $\mathrm{al}^{76}$ found that 3.1-3.9 pyrrole monomer units neutralized one DPPH radical.

Table 3 shows the time-dependent antioxidant activity for the fixed amounts ( $1 \mathrm{wt} \%$ ) of $\mathrm{Ppy} / \mathrm{ZnO} / \mathrm{CS}$ nanocomposite with various ratios of $\mathrm{ZnO} N P s$. The results showed that the antioxidant activity of nanocomposite was enhanced from 74.814 to 79.169 with the increase of $\mathrm{ZnO}$ NP content within less than 100 minutes. Consequently, there was a significant increase in the antioxidant activity of the material with the addition of $\mathrm{ZnO}$ NPs. This finding indicates that the antioxidant activity of the BNCs increases up to a certain time ( $\sim 100$ minutes). In addition, the rate of DPPH inhibitory effect decreases, indicating that there is no more proton or electron transfer to the DPPH free radical. ${ }^{76}$ Furthermore, the increase rate of antioxidant activity decreases in $0-100$ minutes, according to the $\mathrm{ZnO} \mathrm{NP}$

Table 3 Time-dependent antioxidant activity of the Ppy/ZnO/CS bionanocomposite with different content of ZnO nanoparticles

\begin{tabular}{llllll}
\hline Time (min) & \multicolumn{2}{l}{ DPPH inhibition (\%) } & & \\
\cline { 2 - 6 } & Ppy/CS & $\begin{array}{l}\text { Ppy/ZnO/CS } \\
(5 \%)\end{array}$ & $\begin{array}{l}\text { Ppy/ZnO/CS } \\
(\mathbf{1 0 \% )}\end{array}$ & $\begin{array}{l}\text { Ppy/ZnO/CS } \\
(\mathbf{1 5 \% )}\end{array}$ & $\begin{array}{l}\text { Ppy/ZnO/CS } \\
(\mathbf{2 0} \%)\end{array}$ \\
\hline 0 & $52.597 \pm 0.34$ & $74.814 \pm 0.22$ & $76.603 \pm 0.12$ & $77.582 \pm 0.22$ & $79.169 \pm 0.32$ \\
10 & $52.599 \pm 0.16$ & $75.624 \pm 0.27$ & $78.191 \pm 0.32$ & $79.001 \pm 0.42$ & $80.283 \pm 0.22$ \\
20 & $54.726 \pm 0.51$ & $76.468 \pm 0.63$ & $78.359 \pm 0.21$ & $79.574 \pm 0.38$ & $80.452 \pm 0.38$ \\
30 & $54.827 \pm 0.33$ & $78.461 \pm 0.33$ & $78.764 \pm 0.21$ & $80.249 \pm 0.40$ & $80.722 \pm 0.31$ \\
40 & $55.379 \pm 0.45$ & $78.933 \pm 0.43$ & $80.317 \pm 0.35$ & $80.351 \pm 0.25$ & $80.959 \pm 0.40$ \\
50 & $55.604 \pm 0.12$ & $79.574 \pm 0.22$ & $80.453 \pm 0.27$ & $80.621 \pm 0.27$ & $81.127 \pm 0.34$ \\
60 & $56.110 \pm 0.35$ & $80.553 \pm 0.36$ & $80.689 \pm 0.29$ & $81.499 \pm 0.33$ & $82.309 \pm 0.30$ \\
70 & $56.178 \pm 0.24$ & $81.161 \pm 0.38$ & $81.769 \pm 0.37$ & $82.376 \pm 0.52$ & $82.984 \pm 0.33$ \\
80 & $56.988 \pm 0.28$ & $81.836 \pm 0.41$ & $82.073 \pm 0.22$ & $82.478 \pm 0.31$ & $83.389 \pm 0.29$ \\
90 & $58.541 \pm 0.51$ & $82.174 \pm 0.27$ & $83.355 \pm 0.41$ & $83.491 \pm 0.36$ & $83.693 \pm 0.22$ \\
100 & $58.912 \pm 0.33$ & $84.065 \pm 0.23$ & $83.794 \pm 0.19$ & $83.558 \pm 0.22$ & $84.166 \pm 0.43$ \\
\hline
\end{tabular}

Note: Data shown are mean \pm standard deviation.

Abbreviations: Ppy, polypyrrole; CS, chitosan; ZnO, zinc oxide; DPPH, 2,2-diphenyl-I-picrylhydrazyl; min, minutes. 
amount. This confirms that the antioxidant activity of BNC is attributed to $\mathrm{ZnO}$ NPs, and at higher amounts of $\mathrm{ZnO}$ NPs, all of the DPPH radicals scavenge at the initial times of the reaction. Additionally, the rate of reaction with DPPH radicals is numerous, and some parts are less accessible or require a higher potential to be oxidized and thus react more slowly with DPPH radicals. ${ }^{77}$ Also, the radical scavenger ability of the nanocomposite in DPPH solution is affected by the dispersity rate, preparation method, overoxidation, solvent, and size of material. ${ }^{78-80}$

\section{Conclusion}

The conductive BNC films of Ppy, CS, and ZnO NPs were electrochemically deposited using the potentiostatic method on the ITO glass substrate. The results of FTIR, XRD, and SEM analyses showed the formation of composite films that contained ZnO NPs in a Ppy/CS matrix. The electrical conductivity measurement and the DMA results showed that the enhanced conductivity and mechanical properties of the prepared conducting polymer BNC films were due to the presence of ZnO NPs in the composite films. The enhancement of the storage modulus of Ppy/ZnO/CS NPs composite as compared with Ppy/CS composite indicates that the prepared BNC is much stiffer than the composite without ZnO NPs.

The TGA results showed that thermal stability of the Ppy/ CS composite increased in the presence of $\mathrm{ZnO}$ NPs. The observed antibacterial properties suggest that the $\mathrm{Ppy} / \mathrm{ZnO} /$ CS BNC exhibited good antibacterial activity and can be further developed for application in surgical devices, biosensors, and drug-delivery vehicles. This is due to the biodegradability of CS, with antioxidant and antibacterial properties of $\mathrm{ZnO}$ NPs and the electrical properties of Ppy.

\section{Disclosure}

The authors declare no conflicts of interest.

\section{References}

1. Reungurai A, Promjun A, Ouajai WP, Ouajai S. Synthesis of highly conductive polypyrrole nanoparticles via microemulsion polymerization. J Met Mater Miner. 2008;18:27-31.

2. Gospodinova N, Terlemezyan L. Conducting polymers prepared by oxidative polymerization: polyaniline. Prog Polym Sci. 1998;23: 1443-1484.

3. Jin S, Cong S, Xue G, Xiong H, Mansdorf B, Cheng SZD. Anisotropic polythiophene films with high conductivity and good mechanical properties via a new electrochemical synthesis. Adv Mater. 2002;14(20):1492-1496.

4. González-Tejera MJ, Sánchez de la Blanca E, Carrillo I. Polyfuran conducting polymers: synthesis, properties, and applications. Synth Met. 2008;158:165-189.

5. Wang X, Gu X, Yuan C, et al. Evaluation of biocompatibility of polypyrrole in vitro and in vivo. J Biomed Mater Res A. 2004;68:411.
6. Jiang X, Marois Y, Traore A, et al. Tissue reaction to polypyrrole-coated polyester fabrics: an in vivo study in rats. Tissue Eng. 2002;8:635.

7. George PM, Lyckman AW, LaVan DA, et al. Fabrication and biocompatibility of polypyrrole implants suitable for neural prosthetics. Biomaterials. 2005;26:3511.

8. Cui X, Hetke JF, Wiler JA, Anderson DJ, Martin DC. Electrochemical deposition and characterization of conducting polymer polypyrrole/PSS on multichannel neural probes. Sens Actuators A. 2001;93:8.

9. Schmidt CE, Shastri VR, Vacanti JP, Langer R. Stimulation of neurite outgrowth using an electronically conducting polymer. Proc Natl Acad Sci US A. 1997;94:8948.

10. Kamalesh S, Tan P, Wang J, Lee T, Kang ET, Wang CH. Biocompatibility of electroactive polymers in tissues. J Biomed Mater Res. 2000; 52:467.

11. Oh EJ, Jang KS, Diarmid AG. High molecular weight soluble polypyrrole. Synth Met. 2002;125:267-272.

12. Sangawar VS, Moharil NA. Study of electrical, thermal and optical behavior of polypyrrole filled PVC: PMMA thin film thermoelectrets. Chem Sci Trans. 2012;1(2):447-455.

13. Iroh JO, Levine K. Electrochemical synthesis of polypyrrole/polyimide conducting composite using polyamic acid precursor. Eur Polymer J. 2002;38:1547-1550.

14. Ghalib H, Abdullah I, Daik R. Synthesis of polypyrrole nanoparticles in natural rubber-polystyrene blend via emulsion polymerization. $J \mathrm{Appl}$ Polym Sci. 2011;123(4):2115-2121.

15. Xing S, Zhao G, Yuan Y. Preparation of polyaniline-polypyrrole composite submicro fibers via interfacial polymerization. Polym Compos. 2008;29:22-26.

16. Papathananassiou AN, Sakellis I, Grammatikakis J, Sakkopoulos S, Vitoratos E, Dalas E. Effect of hydrostatic pressure on the d.c. conductivity of fresh and thermally aged polypyrrole-polyaniline conductive blends. J Phys D Appl Phys. 2002;35:85-87.

17. Razaq A, Mihranyan A, Welch K, Nyholm L, Strømme M. Influence of the type of oxidant on anion exchange properties of fibrous cladophora cellulose/polypyrrole composites. J Phys Chem B. 2009;113:426-433.

18. Olsson H, Nyström G, Strømme M, Sjödin M, Nyholm L. Cycling stability and self-protective properties of a paper-based polypyrrole energy storage device. Electrochem Commun. 2011;13:869-871.

19. Nystrom G, Razaq A, Strømme M, Nyholm L, Mihranyan A. Ultrafast all polymer paper-based batteries. Nano Lett. 2009;9(10):3635-3639.

20. Nyholm L, Nyström G, Mihranyan A, Strømme M. Toward flexible polymer and paper-based energy storage devices. Adv Mater. 2011;23:3751-3769.

21. Müllera D, Rambo CR, Recouvreux DOS, Porto LM, Barra GMO. Chemicalin situpolymerization of polypyrrole on bacterial cellulose nanofibers. Synth Met. 2011;161:106-111.

22. Li W, Mi Jang D, Yong An S, Kim D, Hong S-K, Kim H. Polyanilinechitosan nanocomposite: high performance hydrogen sensor from new principle. Sens Actuators B Chem. 2011;160:1020-1025.

23. Ye D, Luo L, Ding L, Chen Q, Liu X. A novel nitrite sensor based on graphene/polypyrrole/chitosan nanocomposite modified glassy carbon electrode. Analyst. 2011;136:4563-4569.

24. Gelin K, Mihranyan A, Razaq A, Nyholm L, Strømme M. Potential controlled anion absorption in a novel high surface area composite of Cladophora cellulose and polypyrrole. Electrochim Acta. 2009;54:3394-3401.

25. Carlsson DO, Nystrom G, Zhou Q, Berglund LA, Nyholm L, Strømme M. Electroactive nanofibrillated cellulose aerogel composites with tunable structural and electrochemical properties. J Mater Chem. 2012;22:19014-19024.

26. Razaq A, Nystrom G, Strømme M, Mihranyan A, Nyholm L. High-capacity conductive nanocellulose paper sheets for electrochemically controlled extraction of DNA oligomers. PLos One. 2011;6(12):e29243.

27. Li Y, Li G, Peng H, Chen K. Facile synthesis of electroactive polypyrrole-chitosan composite nanospheres with controllable diameters. Polym Int. 2011;60(4):647-651. 
28. Sasso C, Zeno E, Petit-Conil M, et al. Benevent D. Highly conducting polypyrrole/cellulose nanocomposite films with enhanced mechanical properties. Macromol Mater Eng. 2010;295(10):934-941.

29. Abdi M, Kassim A, Ekramul Mahmud HNM, Yunus WMM, Talib ZA. Physical, optical and electrical properties of a new conducting polymer. J Materials Sci. 2009;44:3682-3686.

30. Honglue T, Rui M, Chucheng L, Ziwei L, Tingting T. Quaternized chitosan as an antimicrobial agent: antimicrobial activity, mechanism of action and biomedical applications in orthopedics. Int $J$ Mol Sci. 2013;14:1854-1869.

31. Süleyman Y, Cahit D, Mahir T, Nureddin Ç. Electrochemical synthesis and characterization of polypyrrole/chitosan composite on platinum electrode: its electrochemical and thermal behaviors. Carbohydr Polym. 2010;79:908-913.

32. Fang Y, Ni Y, Zhang G, Mao C, Huang X, Shen J. Biocompatibility of CS-Ppy nanocomposites and their application to glucose biosensor. Bioelectrochemistry. 2012;88:1-7.

33. Agnihotri SA, Mallikarjuna NN, Aminabhavi TM. Recent advances on chitosan-based micro- and nanoparticles in drug delivery. J Control Release. 2004;100(1):5-28.

34. Darder M, Colilla M, Ruiz-Hitzky E. Chitosan-clay nanocomposites: application as electrochemical sensors. Appl Clay Sci. 2005;28:199-208.

35. Beecroft LL, Ober CK. Nanocomposite materials for optical applications. Chem Mater. 1997;9:1302-1317.

36. Sanchez C, Soler-Illia GJdeAA, Ribot F, Lalot T, Mayer CR, Cabuil V. Designed hybrid organic-inorganic nanocomposites from functional nanobuilding blocks. Chem Mater. 2001;13:3061-3083.

37. Gangopadhyay R, De A. Conducting polymer nanocomposites: a brief overview. Chem Mater. 2000;12:608-622.

38. Mitzi DB. Thin-film deposition of organic-inorganic hybrid materials. Chem Mater. 2001;13:3283-3298.

39. Yu-Chen T, Shih-Ci L, Shang-Wei L. Electrodeposition of polypyrrolemultiwalled carbon nanotube-glucose oxidase nanobiocomposite film for the detection of glucose. Biosens Bioelectron. 2006;22:495-500.

40. Chougule MA, Dalavi DS, Mali S, et al. Novel method for fabrication of room temperature polypyrrole- $\mathrm{ZnO}$ nanocomposite $\mathrm{NO}_{2}$ sensor. Measurement. 2011;04:023.

41. Butterworth MD, Corradi R, Johal J, Lascelles SF, Maeda S, Armes SP. Zeta potential measurements on conducting polymer-inorganic oxide nanocomposite particles. J Colloid Interface Sci. 1995;174:510.

42. Bower DI. An Introduction to Polymer Physics. Cambridge, UK: Cambridge University Press; 2002.

43. Singh SP, Arya SK, Pandey MK, et al. Cholesterol biosensor based on rf sputtered zinc oxide nanoporous thin film. Appl Phys Lett. 2007;91:063901.

44. Wei A, Sun XW, Wang JX, et al. Zinc oxide nanocomb biosensor for glucose detection. Appl Phys Lett. 2006;99:123902.

45. Wang JX, Sun XW, Wei A, et al. ZnO nanocomb biosensor for glucose detection. Appl Phys Lett. 2006;88:233106.

46. Guernion N, de Lacy Costello BPJ, Ratcliffe NM. The synthesis of 3-octadecyl and 3-docosylpyrrole, their polymerisation and incorporation into novel composite gas sensitive resistors. Synth Met. 2002;128(2):139-147.

47. Zhitomirsky I. Electrophoretic deposition of organic-inorganic nanocomposites. J Mater Sci. 2006;41:8186-8195.

48. Zhitomirsky I. Cathodic electrodeposition of ceramic and organoceramic materials: fundamental aspects. Adv Colloid Interface Sci. 2002;97:277-315

49. Soares JR, Dinis TCP, Cunha AP, Almeida LM. Antioxidant activities of some extracts of thymus zygis. Free Radic Res. 1997;26:469-478.

50. Loyalka SK, Riggs CA. Inverse problem in diffuse reflectance spectroscopy. Appl Spectrosc. 1995;49:1107.

51. Kwon YJ, Kim KH, Lim CS, Shim KB. Characterization of ZnO nanopowders synthesized by the polymerized complex method via an organochemical route. Journal of Ceramic Processing Research. 2002;3:146-149.

52. Wahab R, Ansari SG, Kim YS, Song M, Shin H-S. The role of $\mathrm{pH}$ variation on the growth of zinc oxide nanostructures. Appl Surf Sci. 2009;255:4891-4896.
53. Umar A, Rahman MM, Vaseem M, Hahn Y-B. Ultra-sensitive cholesterol biosensor based on low-temperature grown $\mathrm{ZnO}$ nanoparticles. Electrochem commun. 2009;11:118-121.

54. Murugan R, Ramakrishna S. Bioresorbable composite bone paste using polysaccharide based nano hydroxyapatite. Biomaterials. 2004;25: 3829-3835.

55. Coelho TC, Laus R, Mangrich AS, de Fávere VT, Laranjeira MCM. Effect of heparin coating on epichlorohydrin cross-linked chitosan microspheres on the adsorption of copper (II) ions. React Funct Polym. 2007;67:468-475.

56. Guan B, Wu W, Ni, Z, Lai Y. Removal of Mn(II) and Zn(II) ions from flue gas desulfurization wastewater with water-soluble chitosan. Separation and Purification Technology. 2009;65:269-274.

57. Wang X, Du Y, Liu H. Preparation, characterization and antimicrobial activity of chitosan-Zn complex. Carbohydr Polym. 2004;56:21-26.

58. Mitchell GR, Geri A. Molecular organisation of electrochemically prepared conducting polypyrrole films. J Phys D Appl Phys. 1987;20: 1346-1353.

59. Kassim A, Block H, Davis FJ, Mitchell GR. Anisotropic films of polypyrrole formed electrochemically using a non-planar dopant. $J$ Mater Chem. 1992;2:987-988.

60. Mohammad F. Compensation behaviour of electrically conductive polythiophene and polypyrrole. J Phys D Appl Phys. 1998;31: 951-959.

61. Ghosh M, Barman A, Das A, Meikap AK, De SK, Chatterjee S. Electrical transport in paratoluenesulfonate doped polypyrrole films at low temperature. J Appl Phys. 1998;83:4230.

62. Hakansson E, Lin T, Wang H, Kaynak A. The effects of dye dopants on the conductivity and optical absorption properties of polypyrrole. Synth Met. 2006;156(18-20):194-1202.

63. Cuero R, Lillehoj E. N-carboxymethylchitosan: algistatic and algicidal properties. Biotechnol Lett. 1990;4:275.

64. Muzzarelli RAA, Muzzarelli C, Tarsi R, Miliani M, Gabbanelli F, Cartolari M. Fungistatic activity of modified chitosans against Saprolegnia. parasitica. Biomacromolecules. 2001;2:165-169.

65. Sosa MA, Azley F, Koch JA, Vercellotti SV, Ruprecht RM. $\mathrm{N}$-carboxymethylchitosan-N,O-sulfate as an anti-HIV-1 agent. Biochem Biophys Res Commun. 1991;174:489.

66. Jolles P, Muzzarelli RAA, editors. Chitin and Chitinases. Basel, Switzerland: Birkhauser; 1999.

67. Franklin TJ, Snow GA. Biochemistry of Antimicrobial Action. London, UK: Chapman and Hall; 1981.

68. Takemono K, Sunamoto J, Askasi M. Polymers and Medical Care. Tokyo, Japan: Mita; 1989; Chapter IV.

69. Li Y, Zou Y, An D, Hou Y, Zhou Q, Zhang L. Investigation of antibacterial properties of Nano- $\mathrm{ZnO}$ assembled cotton fibers. Fibers and Polymers. 2013;14(6):990-995.

70. Morones JR, Elechiguerra JL, Camacho A, et al. The bactericidal effect of silver nanoparticles. Nanotechnology. 2005;16:2346-2353.

71. Lee D, Cohen RE, Rubner MF. Antibacterial properties of Ag nanoparticle loaded multilayers and formation of magnetically directed antibacterial microparticles. Langmuir. 2005;21:9651-9659.

72. Lok CN, Ho CM, Chen R, et al. Proteomic analysis of the mode of antibacterial action of silver nanoparticles. J Proteome Res. 2006;5: 916-924.

73. Sawai J. Quantitative evaluation of antibacterial activities of metallic oxide powders $(\mathrm{ZnO}, \mathrm{MgO}$ and $\mathrm{CaO})$ by conductimetric assay. J Microbiol Methods. 2003;54:177-182.

74. Yoon K, Byeon JH, Park J, Hwang J. Susceptibility constants of Escherichia coli and Bacillus subtilis to silver and copper nanoparticles. Sci Total Environ. 2007;373:572-575.

75. Ruparelia JP, Kumar Chatterjee A, Duttagupta SP, Diao M, Yao M. Use of zero-valent iron nanoparticles in inactivating microbes. Water Res. 2009;43:5243-5251.

76. Hsu CF, Zhang L, Peng H, Travas-Sejdic J, Kilmartin PA. Scavenging of DPPH free radicals by polypyrrole powders of varying levels of overoxidation and/or reduction. Synth Met. 2008;158:946-952. 
77. Lee RJ, Temmer R, Tamm T, Aabloo A, Kiefer R. Renewable antioxidant properties of suspensible chitosan-polypyrrole composites. React Funct Polym. 2013;73:1072-1077.

78. Lee RJ, Tamm T, Temmer R, Aabloo A, Kiefer R. Two formation mechanisms and renewable antioxidant properties of suspensible chitosan-Ppy and chitosan-Ppy-BTDA composites. Synth Met. 2013; 164:6-11.
79. Marinova G, Batchvarov V. Evaluation of the methods for determination of the free radical scavenger activity by DPPH. Bulg J Agric Sci. 2011;17(1):11-24.

80. Kumar A, Somik B. Size dependent antioxidant activity of polypyrrole nanofibers. AIP Conf Proc. 2011;1349:399-400.
International Journal of Nanomedicine

\section{Publish your work in this journal}

The International Journal of Nanomedicine is an international, peerreviewed journal focusing on the application of nanotechnology in diagnostics, therapeutics, and drug delivery systems throughout the biomedical field. This journal is indexed on PubMed Central, MedLine, CAS, SciSearch $®$, Current Contents $\circledR /$ Clinical Medicine,

\section{Dovepress}

Journal Citation Reports/Science Edition, EMBase, Scopus and the Elsevier Bibliographic databases. The manuscript management system is completely online and includes a very quick and fair peer-review system, which is all easy to use. Visit http://www.dovepress.com/ testimonials.php to read real quotes from published authors.

Submit your manuscript here: http://www.dovepress.com/international-journal-of-nanomedicine-journal 